\title{
With EnginEarrings, Students Profit from Metal Processing Basics
}

\section{Maureen Byko}

Snugly fixed on the Lego-themed tie Daniel Grice wears when he is in business mode is a round, shiny example of what happens when materials science and entrepreneurship intersect: an aluminum tie tack. And dangling from the earlobes of Emilie Siverling when she steps out of her role as student of materials science and into that of conference exhibitor are artful reminders of the lessons of her freshman year: aluminum earrings, punched, annealed, and etched on campus.

On their clothing, in their ears, and on a display table, the University of Wisconsin-Madison students exhibited their wares at the TMS 2009 Annual Meeting in March. Jewelry, tie tacks, and key chains were sold by a team of nine students who attended the meeting, splitting their time between working the exhibit and attending technical sessions.
On a Tuesday afternoon at the exhibit hall, passersby took a break from looking at the latest in processing equipment and shopped at the EnginEarrings booth, purchasing some souvenirs and learning a little about the university and its students in the process. Working the booth at that time were Grice, Siverling, and Nick Thompson, all seniors (Figure 1).

The jewelry production has been in place for years at the university, Siverling said, with the pieces sold at conferences and on campus. For the TMS Annual Meeting, students worked in advance to produce enough pieces-this year, about 100 total-to meet demand. Siverling and Thompson have focused their studies in recent years on polymers and biomaterials, so the metal working was an enjoyable throwback to earlier times, they agreed.

To prepare the metal for sale, the stu-

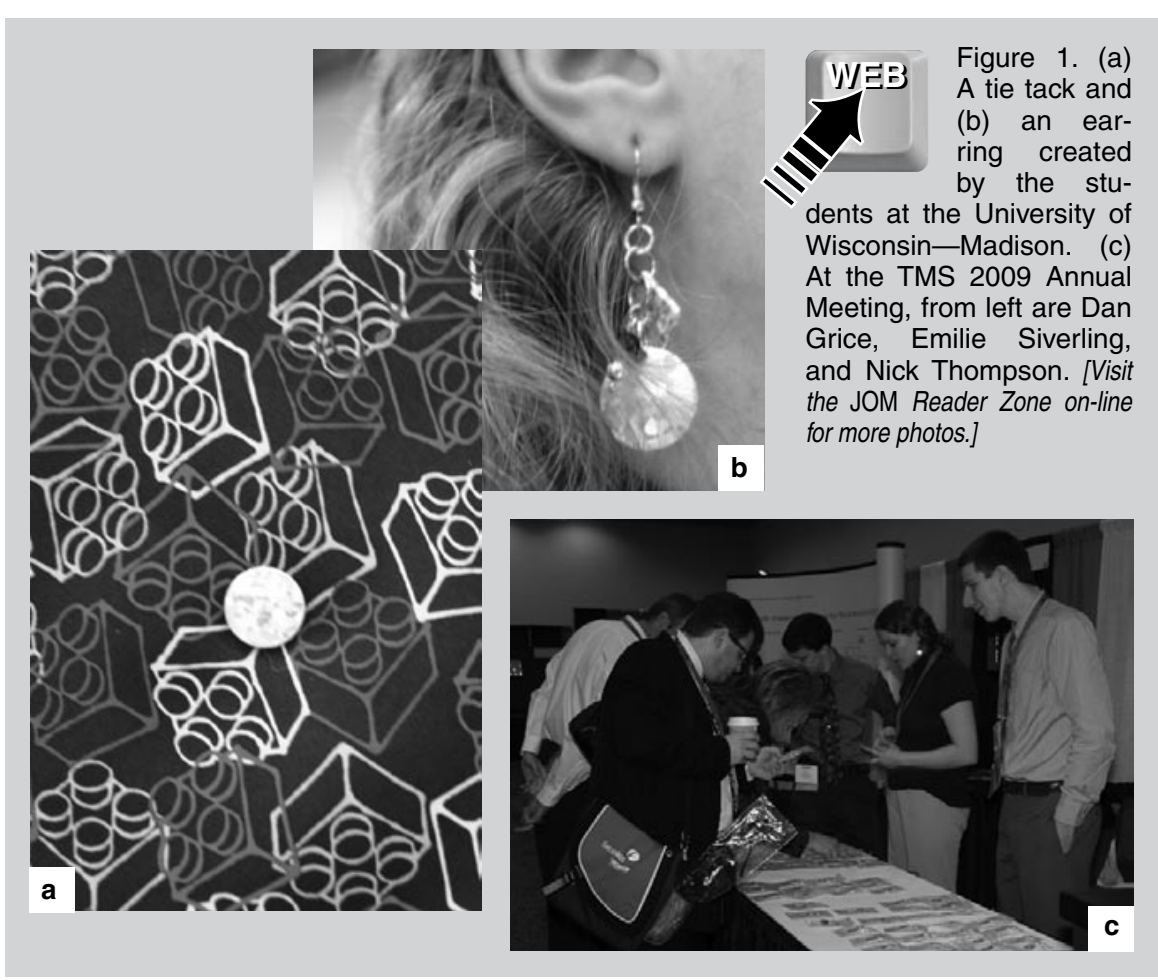

dents etch commercial-purity aluminum in a two-part process. First, a sodium hydroxide solution is used to remove most of the surface oxide, Grice said. Then, the grain contrast is revealed with Poulton's Reagent, which is a mixture of hydrofluoric acid, hydrochloric acid, and nitric acid. "It takes us back to our roots," Grice said of the production. "It takes me back to John Perepezko's class." In that introductory class, Perepezko would etch a piece of brass with gallium to bring out the grain structure, and pass the sample around so his students could break off pieces. The dramatic demonstration remains a fond memory for the three students. "All of us remember that class," Thompson said.

The value of a tactile materials lesson is not lost on the University of Wisconsin. In April, the entire College of Engineering will open up to area children from kindergarten through high school and beyond for its "Engineering Expo," three days of hands-on science and engineering. Held every other year, the event is hosted by the College of Engineering, with undergraduate and graduate students leading the activities. The earrings will be on sale then, Siverling said, and a variety of demonstrations and competitions will allow the university students to practice explaining science in everyday terms.

Although Thompson, Siverling, and Grice will graduate from the under-graduate program and, by default, EnginEarrings, this year, next year a new team of students will visit the TMS annual meeting. It's a longtime tradition, Siverling said, and with continued strong financial support from the university, TMS travel grants, and proceeds of the jewelry sales, she expects it to continue.

Maureen Byko is editor of JOM. 